\title{
Performance of a novel fluorescent-tagged polyacrylate at a cooling tower test facility: a bench-scale and industrial-scale evaluation
}

\author{
S. Kamagurov, ${ }^{1}$ M. Oshchepkov, ${ }^{1,2}$ D.G. Nazarov, ${ }^{3}$ S. Mancini, ${ }^{4}$ \\ K. Popov, ${ }^{1}$ S. Tkachenko ${ }^{1,2}$ and G. Rudakova ${ }^{1}$
}

${ }^{1}$ PJSC "Fine Chemicals R\&D Centre”, Krasnobogatyrskaya, 42, str.1, 107258 Moscow, Russian Federation

${ }^{2}$ Mendeleev University of Chemical Technology of Russia, Miusskaya sq. 9, 125047

Moscow, Russian Federation

${ }^{3}$ EMEC Russia LLC, 123423, Narodnogo Opolchenia street, 34 bld.3 office 214, Moscow, Russian Federation

${ }^{4}$ EMEC SRL, Via Donatori di Sangue, 1 - 02100 Rieti, Italy

*E-mail:ki-popov49@yandex.ru

\begin{abstract}
The ability of fluorescent 1,8-napthalimide-tagged polyacrylate PAA-F1 to serve as an "on line" indicator of polymeric scale inhibitor concentration has been tested in dynamic bench scale tests operating with EMEC facility, and in an industrial-scale in situ experiment run at a "Rosinka 10/20" cooling tower that provides the circulating water cooling of heat exchangers at rectification columns of ECOS-1 Co. site in Staraya Kupavna city, Russia. It has been demonstrated that the static beaker tests and the dynamic bench- and industrialscale experiments may reveal rather different results. The latter exhibited a much higher sensitivity to the background iron cation concentration. It has been found that PAA-F1 may lose up to $17 \%$ of fluorescence intensity, while the losses of indifferent tracer, tetrasodium salt of 1,3,6,8-pyrenetetrasulfonic acid (PTSA) can exceed 80\%. The Bench-scale dynamic experiments on the fluorescence intensity of a fluorescent-tagged scale inhibitor at elevated concentrations of the background cations are recommended as an inevitable step for a proper estimation of fluorescent tracer validity for in situ applications. An industrial-scale 30-day experiment has demonstrated a good agreement of the fluorescent data with the conventional methods of cooling water control, and the feasibility of 1,8-naphthalimide tagged polyacrylate PAA-F1 application for in situ polymer concentration monitoring "on line".
\end{abstract}

Received: July 10, 2018. Published: September 4, 2018 doi: $\underline{10.17675 / 2305-6894-2018-7-3-11}$

Keywords: water treatment, 1,8-napthalimide-tagged polyacrylate, scale inhibition, fluorescence, in situ polyacrylate concentration monitoring. 


\section{Introduction}

The application of chemical inhibitors is a widely used technique for controlling scale deposition in cooling water systems [1,2]. Among these, polyacrylates are considered as an effective solution [3-5]. However, the concentration of polymeric antiscalants in a circulating system is usually changed by evaporation of water, reagent sorption on the pipe surfaces and scale particles, and by a periodical discharge of the circulating water with some deposit. Therefore, adequate monitoring of the polymer concentration is needed to minimize the consumption of both a scale inhibitor and water. Along with conventional monitoring methods based on UV-VIS or potentiometry [6], the intensity of fluorescence emitted from a tracer covalently bound to a polymer, becomes a matter of choice [7-11]. Meanwhile, most of these reports are based on the beaker-level experiments [12]. Although the numerous water treatment companies worldwide have patented the fluorescent-tagged antiscalants and arranged the industrial production of these chemicals (Nalco Company, USA [13, 14]; Ecolab USA Inc., USA [15]; Kemira Chemicals Inc., USA [16]; Rhodia Chimie, France [17]; PJSC "Fine Chemicals R\&D Centre", Russia [18]; ConocoPhillips Co., USA; Advanced Analytical Technologies, Inc. [19]; Shandong Sunway Landscape Technology Co., Ltd., Peop. Rep. China [20]), the publications on their industrial scale applications are missing.

Present communication is focused on a bench-scale and industrial scale evaluation of the antiscaling and fluorescent activity of a novel 1,8-naphthalimide tagged polyacrylate PAA-F1 [9] (Scheme 1). For the bench-scale experiments, the 1,3,6,8-pyrenetetrasulfonic acid tetrasodium salt, PTSA (Scheme 1) was tested as a reference for PAA-F1.

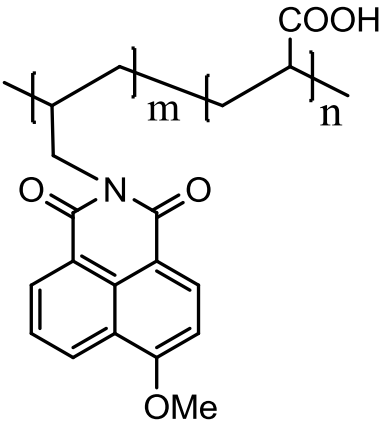

PAA-F1<smiles>O=S(=O)(O[Na])c1cc(S(=O)(=O)O[Na])c2ccc3c(S(=O)(=O)O[Na])cc(S(=O)(=O)O[Na])c4ccc1c2c43</smiles>

PTSA

Scheme 1. PAA-F1 and PTSA molecular structures.

The main objectives of the present study included: (i) the study of an iron cation influence on the tracer fluorescence intensity, and (ii) the feasibility study of a scale inhibitor fluorescent marker application in the real water treatment industrial facilities. 


\section{Experimental}

\subsection{Materials and methods}

The 1,8-napthalimide-tagged polyacrylate PAA-F1 with molecular mass 3000 to $5000 \mathrm{Da}$. was synthesized as described elsewhere [9]. The fluorescent fragment F1 constituted $0.5 \%$ (mass) of the total polymer mass. 1,3,6,8-Pyrenetetrasulfonic acid tetrasodium salt, PTSA was supplied by Spectra Colors Corporation.

Moscow tap water was used in the bench-scale experiments ( $\mathrm{pH} 7.2$; water hardness: $2.4 \mathrm{mg}$-equiv $\cdot \mathrm{dm}^{-3}$ ), while the industrial tests have been run with the Old Kupavna city tap water ( $\mathrm{pH} 8.7$; water hardness: $5.5 \mathrm{mg}$-equiv $\cdot \mathrm{dm}^{-3}$; iron cations: $\left.1.6 \mathrm{mg} \cdot \mathrm{dm}^{-3}\right)$. Water hardness was measured by EDTA-titration. Where appropriate, reagent grade iron(III) chloride was used as an additive.

The fluorescence intensity measurements were performed using a flow-through fluorometric probe, ETRC (bench-scale tests) and a RF-6000 (Shimadzu) spectrofluorimeter (industrial-scale experiment). In the latter case the water was periodically sampled from the cooling water system. The excitation $\left(\lambda^{\mathrm{ex}}\right)$ was measured at $375 \mathrm{~nm}$ ( $\lambda^{\mathrm{ex}}$ - wavelength that corresponds to the maximal light absorption), $1 \mathrm{~nm}$ slit width, while emission $\left(\lambda^{\mathrm{em}}\right)-$ at $465 \mathrm{~nm}\left(\lambda^{\mathrm{em}}-\right.$ wavelength that corresponds to the maximal fluorescence), $2 \mathrm{~nm}$ slit width.

\subsection{Bench-scale dynamic experiment}

A bench-scale dynamic experiment was run at the facility specially developed by EMEC company in cooperation with "Fine Chemicals R\&D Centre", Figure 1. This facility models the workflow of a real cooling tower. The reservoir 9 (cooling tower) is filled with 2 liters of a tap water with $50 \mathrm{mg} \cdot \mathrm{dm}^{-3}$ of PAA-F1. Then the pump starts to provide water circulation, and the sensors 2, 5, 6, 7, 8 start to monitor the aqueous phase. All of them are wired to the computer unit. The total experiment time was $450 \mathrm{~min}$. On the $90^{\text {th }}, 170^{\text {th }}$ and $360^{\text {th }}$ minutes $\mathrm{FeCl}_{3}$ was injected in amounts that provided the total iron content of $0.3,1.5$, and $3 \mathrm{mg} \cdot \mathrm{dm}^{-3}$, respectively.

\subsection{Industrial-scale experiment}

The industrial-scale experiment was run at a "Rosinka 10/20" cooling tower that provides circulating water cooling in heat exchangers of rectification columns at ECOS-1 Co. site in Staraya Kupavna city with a total cooling water volume of $4.5 \mathrm{~m}^{3}$, Figure 2 . The hot water from the heat exchangers 12 of the rectification columns goes to the collector of heated water 8. Then it is transferred to the cooling tower G-40 ("Rosinka 10/20") by pump 10. The cooled water is collected in vessel 7, then returned to the heat exchangers (12). The injection of reagents is performed at collectors 7 and 8 from vessel 6 via dosing pump 9 . 


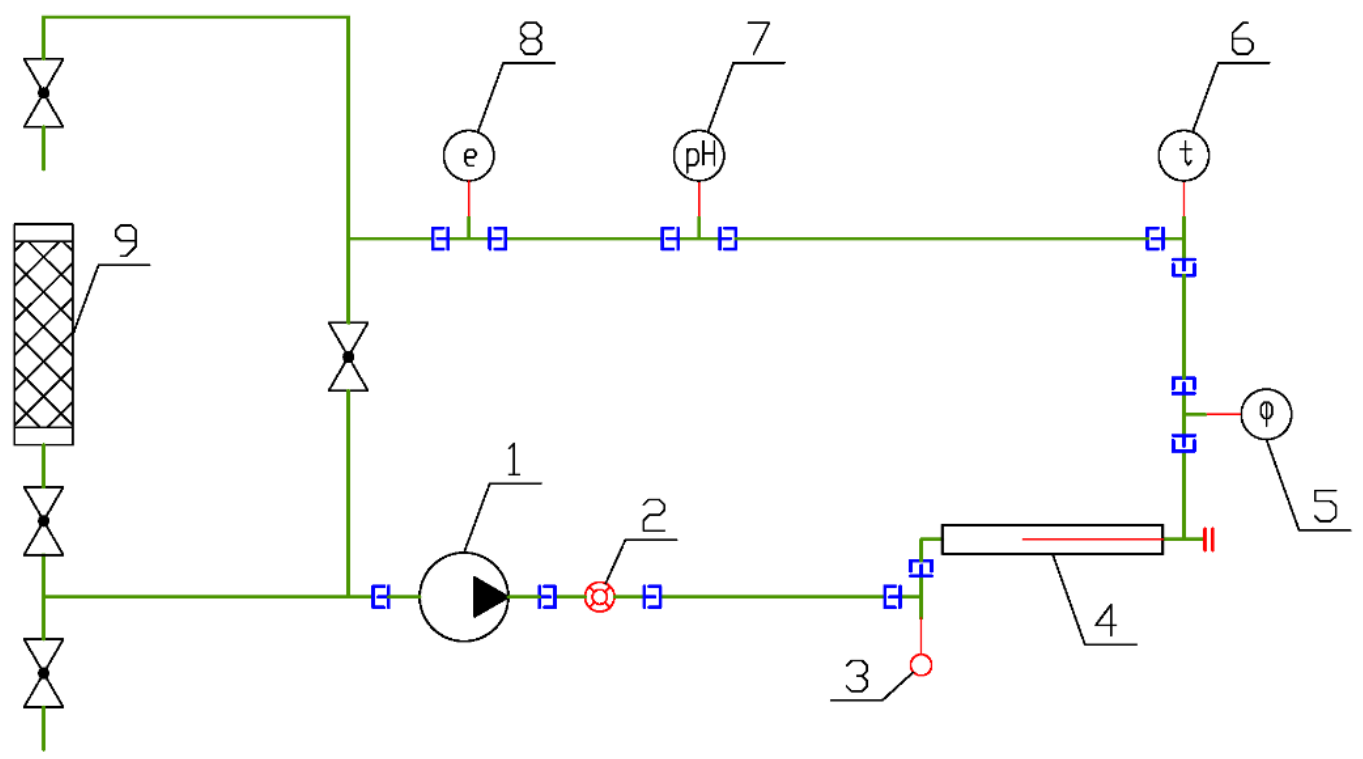

Figure 1. The scheme of a bench-scale facility used for the dynamic experiments: the pump (1); flowmeter (2); the heater (3); corrosion measurements cell (4); flow-through fluorometric probe, ETRC (5), temperature probe, ETEPCH18 (6); pH-probe, EPHS (7), high linearity conductance probe, ECDHL/10 ( 8); simulated cooling tower (9).

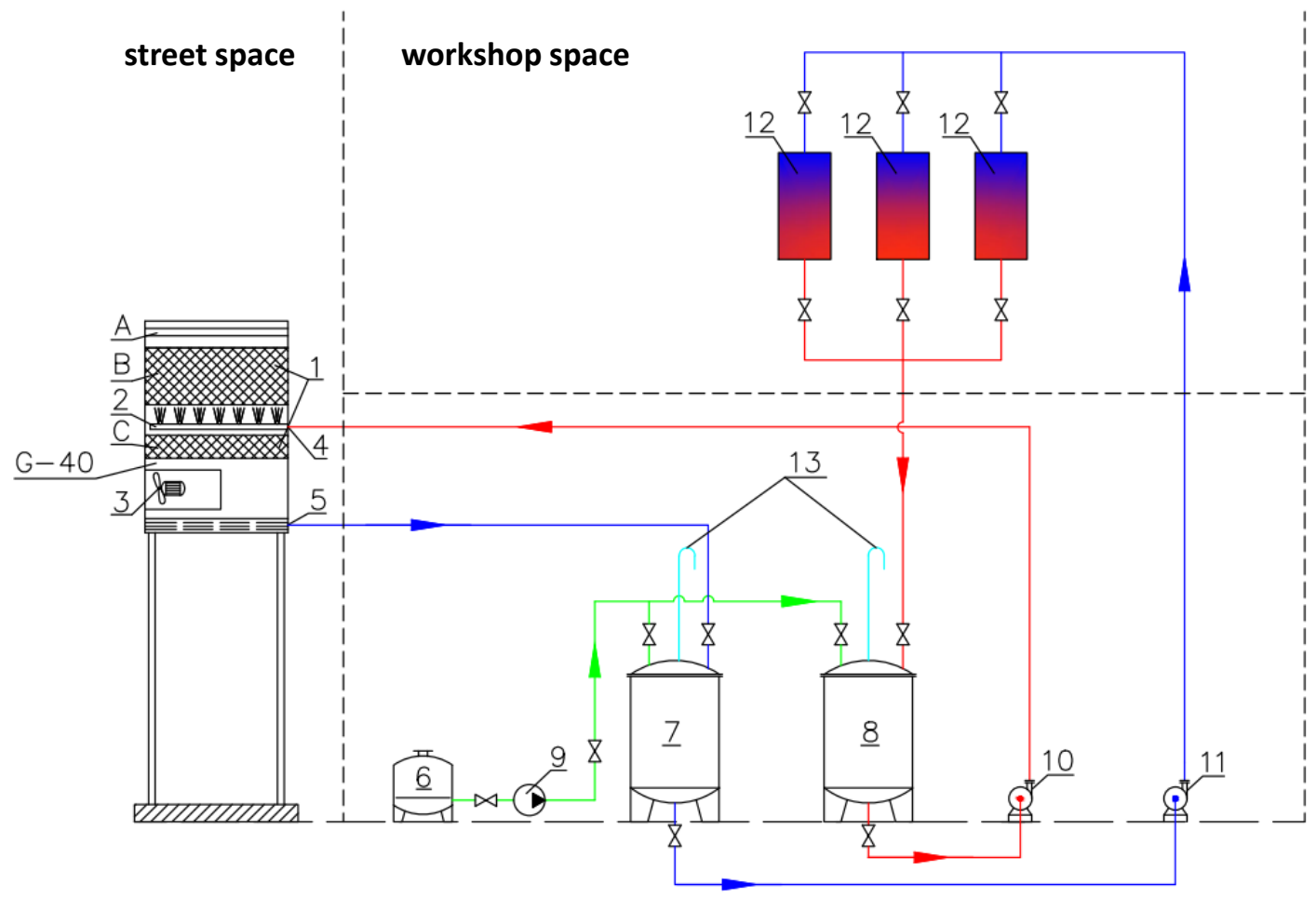

Figure 2. An industrial cooling tower scheme with a rectification column at ECOS-1 Co. site in Staraya Kupavna city. 
An experiment lasted for 30 days. The water samples were taken periodically and analyzed in a parallel way by the classical titration methods for conductance and for fluorescence intensity. A $6 \mathrm{mg} \cdot \mathrm{dm}^{-3}$ dosage of PAA-F1 was used. The natural daily water loss due to evaporation constituted $c a .1 \mathrm{~m}^{3}$. This loss was compensated daily by adding new portions of feed water. Thus the total salinity and PAA-F1 concentration in the cooling water were constantly increasing. On the $10^{\text {th }}$ day of the experiment, the residual water was completely removed from the circuit and a new portion of feed water with PAAF1 was added to the system. On the $30^{\text {th }}$ day the water change was repeated.

\section{Results and Discussion}

\subsection{Bench-scale dynamic experiment}

The Bench-scale dynamic experiments indicate that the fluorescence intensity of PAA-F-1 does not change during the water circulation, Figure 3 . However, the sensitivity to $\mathrm{Fe}^{3+}$ cation concentration appears to be different to that one in the beaker tests. Indeed, a $3 \mathrm{mg} \cdot \mathrm{dm}^{-3}$ dosage injection of iron ions leads to $17 \%$ loss of PAA-F1 intensity, while in the beaker runs the same dosage demonstrated only 2 to $3 \%$ decrease [9].

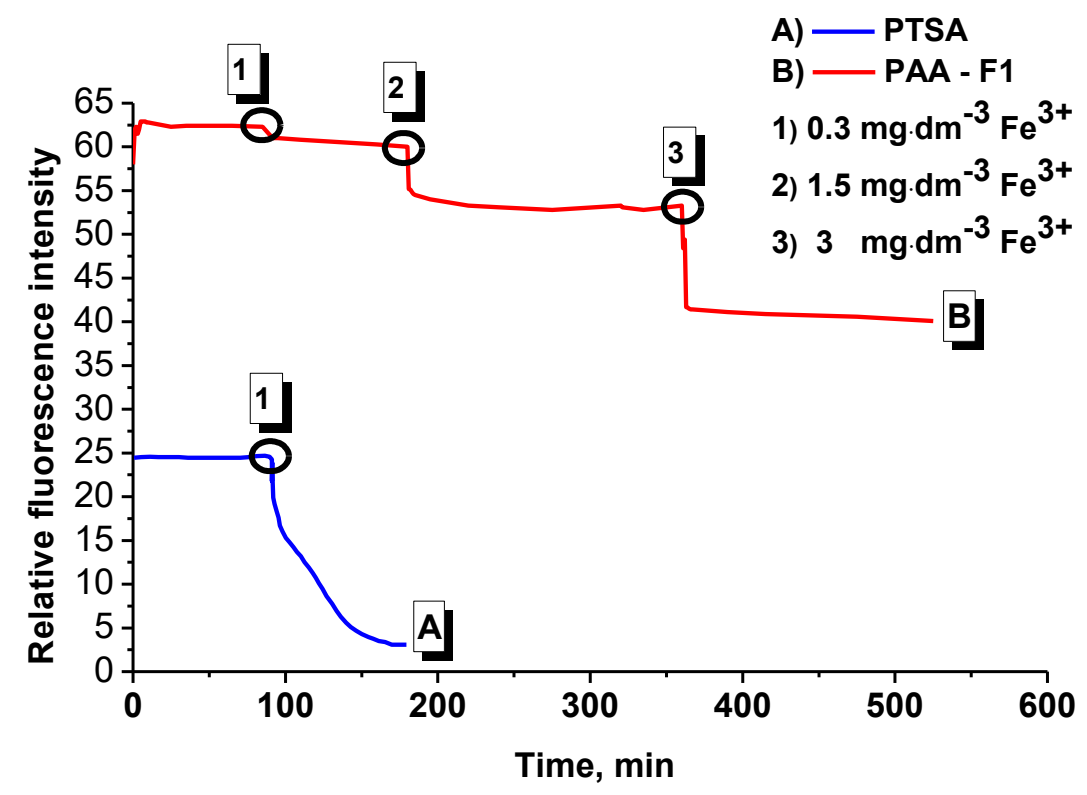

Figure 3. The time dependence of PAA-F1 $\left(50 \mathrm{mg} \cdot \mathrm{dm}^{-3}\right)$ and PTSA $\left(10 \mathrm{mg} \cdot \mathrm{dm}^{-3}\right)$ fluorescence intensity in a bench-scale facility test. The circles indicate the moments of iron salts injections.

At the same time, the PTSA revealed in a parallel test a more drastic fluorescence quenching by iron ions under the same conditions, although in the glass beakers this reagent was insensitive to the background cations. This result indicates that the fluorescent marker has to be inevitably tested for extreme iron concentrations in dynamic conditions before use in situ. 


\subsection{Results of industrial-scale experiment}

The results of industrial-scale experiment are presented in Figure 4. It is demonstrated that within the first 14 days of experiment both the conductance and fluorescence intensity are increasing due to the circulating water evaporation and a corresponding gradual increase in the concentrations of PAA-F1 and the background electrolytes. According to the testing plan the evaporation coefficient was let to increase twice. On the $7^{\text {th }}$ day the total volume of the cooling water was restored by addition of a new portion of feed water with PAA-F1. This operation was reflected by a simultaneous decrease in conductance and fluorescence intensity. It should be noted that no scale formation was registered within this period. Thus the PAA-F1 reveals a good antiscaling ability.

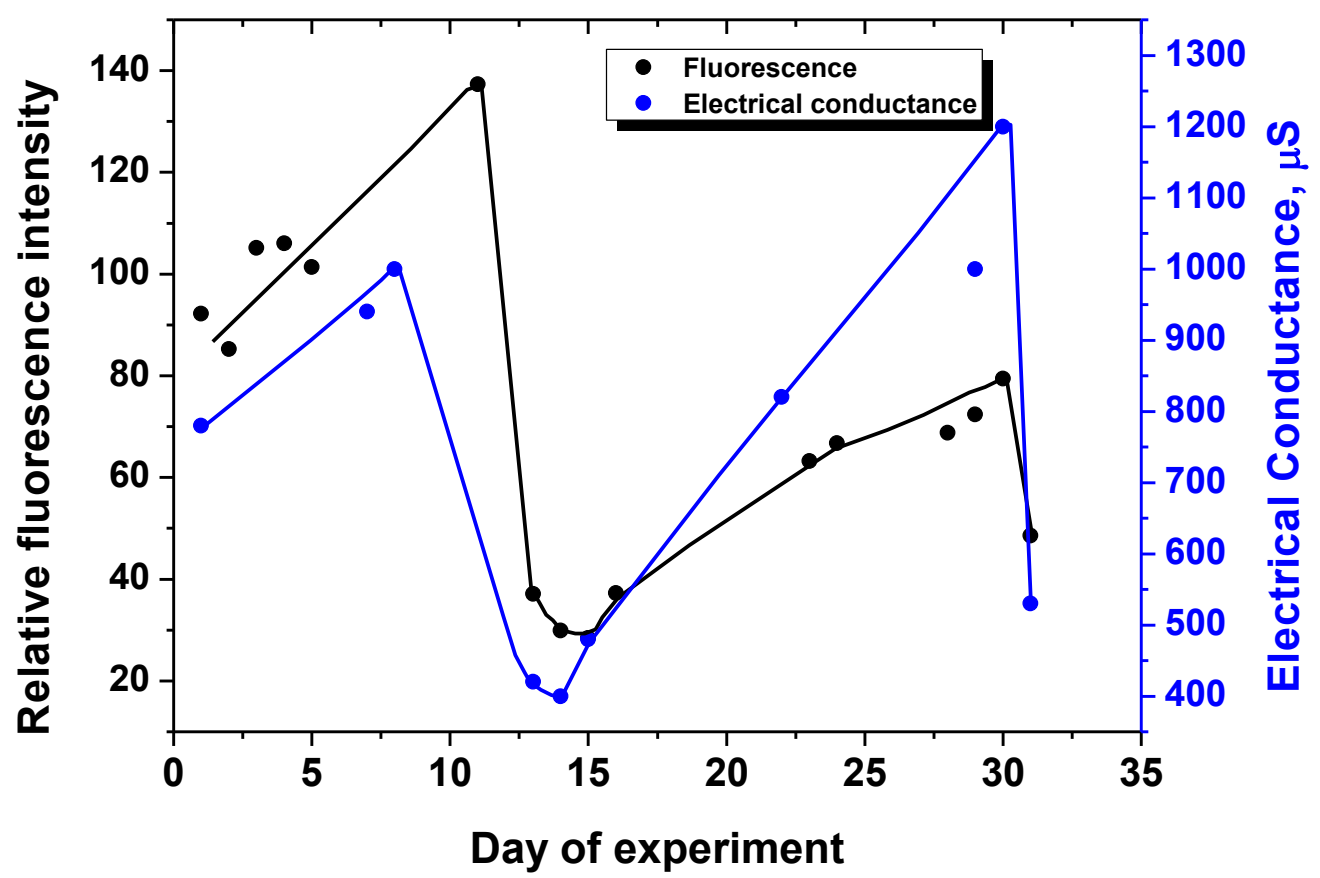

Figure 4. The time dependence of PAA-F1 $\left(6 \mathrm{mg} \cdot \mathrm{dm}^{-3}\right)$ fluorescence intensity and a cooling water conductance at a cooling tower of a rectification column

Then from 15-th to 30-th day of experiment the cooling water evaporation proceeded, and again the growth of both conductance and fluorescence was registered. On the 30-th day the other new portion of feed water was added, and led to an immediate decrease in conductance and fluorescence. This observation was in a good agreement with titrimetric analytical data that revealed the corresponding "increase-decrease" of water hardness. Thus the fluorescent data are in a good agreement with indications of other methods, and are quite valid for monitoring the polymer inhibitor content in the water circulation system. 


\section{Conclusions}

It has been demonstrated that the static beaker tests and the dynamic bench- and industrialscale experiments may reveal sufficiently different results. The bench-scale test exhibited a much higher sensitivity to the background iron cation concentration relative to the beaker one. It has been found that PAA-F1 may lose up to $17 \%$ of fluorescence intensity, while for an indifferent tracer 1,3,6,8-pyrenetetrasulfonic acid tetrasodium salt (PTSA) these losses may exceed $80 \%$.

The Bench-scale dynamic experiments on the fluorescence intensity of a fluorescenttagged scale inhibitor under elevated concentrations of the background cations is an inevitable step for a proper estimation of a fluorescent tracer validity for in situ applications.

An Industrial-scale experiment exhibits the feasibility of 1,8-naphthalimide tagged polyacrylate PAA-F1 application for in situ polymer concentration monitoring "on line", and a good agreement with conventional methods.

\section{Acknowledgement}

The authors would like to thank "Foundation for Assistance to Small Innovative Enterprises (FASIE), (Project No. 11454GU/2017 from 05.15.2017)" for the support of the present study.

\section{References}

1. Z. Amjad, Kinetic and morphological investigation of calcium sulfate dihydrate (gypsum) scale formation on heat exchanger surfaces in the presence of inhibitors, Int. J. Corros. Scale Inhib., 2017, 6, no. 3, 276-290. doi: 10.17675/2305-6894-20176-3-4

2. K.I. Popov, N.E. Kovaleva, G.Ya. Rudakova, S.P. Kombarova and V.E. Larchenko, Recent State-of-the-Art of Biodegradable Scale Inhibitors for Cooling Water Treatment Applications (Review), Therm. Eng., 2016, 63, 122-129. doi: 10.1134/ S0040601516010092

3. K.D. Demadis and M. Preari, "Green" scale inhibitors in water treatment processes: the case of silica scale inhibition, Desalin. Water Treat., 2015, 55, 749-755. doi: 10.1080/19443994.2014.927803

4. X. Li, H. Shemer, D. Hasson and R. Semiat, Characterization of the effectiveness of anti-scalants in suppressing scale deposition on a heated surface, Desalination, 2016, 397, 38-42. doi: 10.1016/j.desal.2016.06.022

5. A. Ketsetzi, A. Stathoulopoulou and K.D. Demadis, Being "Green" in Chemical Water Treatment Technologies: Issues, Challenges and Developments, Desalination, 2008, 223, 487-493. 
6. A. Yuchi, Y. Gotoh and S. Itoh, Potentiometry of effective concentration of polyacrylate as scale inhibitor, Anal. Chim. Acta., 2007, 594, 199-203. doi: 10.1016/j.aca.2007.05.049

7. Zh. Shen, X. Zhi and P.Zhang, Preparation of fluorescent polyaspartic acid and evaluation of its scale inhibition for $\mathrm{CaCO}_{3}$ and $\mathrm{CaSO}_{4}$, Polym. Adv. Technol., 2017, 28, no. 3, 367-372. doi: 10.1002/pat.3897

8. G. Liu, M. Xue and Y. Zhou, Fluorescent-tagged block copolymer as an effective and green inhibitor for calcium sulfate scales, Russ. J. Appl. Chem., 2016, 89, 1861-1868. doi: $10.1134 / \mathrm{S} 1070427216110185$

9. K. Popov, M. Oshchepkov, S. Kamagurov, S. Tkachenko, Ju. Dikareva and G. Rudakova, Synthesis and properties of novel fluorescent-tagged polyacrylate-based scale inhibitors, J. Appl. Polym. Sci., 2017, 134, doi: 10.1002/app.45017

10.H. Wang, Yu.Zhou, Q. Yao and W. Sun, Calcium sulfate precipitation studies with fluorescein-tagged scale inhibitor for cooling water systems, Polym. Bull., 2015, 72, 2171-2188. doi: 10.1007/s00289-015-1396-2

11. T-H. Tran-Thi, C. Prayer, Ph. Millie, P. Uznanski and J.T. Hynes, Substituent and solvent effects on the nature of the transitions of pyrenol and pyranine. Identification of an intermediate in the excited-state proton-transfer reaction, J. Phys. Chem., 2002, 106, 2244-2255. doi: 10.1021/jp0125606

12. M. Oshchepkov and K. Popov, Fluorescent markers in water treatment, in Desalination and Water Treatment, Ed. M. Eyvaz, IntechOpen, 2018 (in press).

13. J.D. Morris, B.E. Moriarty, W. Mingli, P.G. Murray and J.L. Reddinger, Fluorescent monomers and tagged treatment polymers containing same for use in industrial water systems, U.S. Pat. Appl. Publ., 2004, US 20040135125 A1 20040715, Nalco Company, USA.

14. B.E. Moriarty, J.E. Hoots, W. Mingli, D.P. Workman and J.P. Rasimas, Fluorescent monomers and polymers containing same for use in industrial water systems, PCT Int. Appl. 2001, WO 2001044403 A1 20010621, Nalco Company, USA.

15. J.M. Atkins, B.E. Moriarty and P.J. Zinn, Fluorescent monomers and tagged treatment polymers containing same for use in industrial water systems, U.S. Pat. Appl. Publ. 2014, US 20140183140 A1 20140703, Ecolab USA Inc., USA.

16. L. Moore and L. Clapp, Tagged scale inhibitor compositions and methods of inhibiting scale for oil field application, PCT Int. Appl. 2012, WO 2012018683 A1 20120209, Kemira Chemicals Inc., USA.

17. E. Hills and P. Chapon, Tagged scale inhibiting polymers, compositions comprised thereof and preventing or controlling scale formation therewith, U.S. Patent 2011, US 7943058 B2 20110517, Rhodia Chimie, France.

18. S.D. Kamagurov, N.E. Kovaleva, M.S. Oshchepkov, K.I. Popov, S.V. Tkachenko and E.S. Starkova, Fluorophor and method for obtaining salt inhibitor containing fluorophor as fluorescent mark, Russ. Patent 2017, RU 2640339 C2 20171227, PJSC "Fine Chemicals R\&D Centre", Russia. 
19. J.E. Locklear, T. Baugh, P. Varineau and W. Wei, Measurement of scale inhibitor in water systems, PCT Int. Appl. 2016, WO 2016191758 A1 20161201, ConocoPhillips Co., USA, Advanced Analytical Technologies, Inc.

20. Wang Sheng, Fluorescence-marked scale inhibitor and a preparation method thereof, Faming Zhuanli Shenqing 2017, CN Patent 106315873 A 20170111, Shandong Sunway Landscape Technology Co., Ltd., Peop. Rep. China. 